\title{
44554 - A SURVEY: USE OF SAFETY IV CATHETERS IN PEDIATRIC ANESTHESIA PRACTICE
}

\author{
Kimmo Murto, Children's Hospital of Eastern Ontario, Ottawa, ON, Canada; \\ Rob Perverseff, Royal University Hospital; \\ Greg Bryson, The Ottawa Hospital;
}

INTRODUCTION: There are approximately 69,000 sharps device injuries among health-care workers in Canada per year. Anesthesiologists are a high-risk group for needle-stick injury [1]. Safety IV catheters are designed to protect the operator from needle-stick injury. Our objective was to describe the availability and attitude towards safety IV catheters among anesthesiologists practicing in Canadian pediatric tertiary care centers.

METHODS: After ethics committee approval, an initial and identical follow-up survey were distributed via the Internet using Survey Monkey software to anesthesiologists with varying degrees of pediatric practice. E-mail addresses of 236 anesthesiologists were obtained from the Canadian Pediatric Anesthesia Society and by contacting the anesthesiology departments of 16 Canadian pediatric tertiary care centers. The survey questioned demographic characteristics, attitudes towards implementation, perceived usefulness, mechanism of action, availability and frequency of use, and problems with safety IV catheters. Information concerning the number, type and frequency of needlestick injuries was gathered. The survey design accounted for reliability and content validity. All data are described as proportions or medians.

RESULTS: 124 (53\%)surveys were returned. All 16 pediatric tertiary care centers ( 9 freestanding and 7 referral) in Canada were represented. The median age block of respondents was 41-50 years and most had practiced anesthesia between 6 and 25 years. The majority (62\%) had pediatric-based practices accounting for greater than $76 \%$ of their time. Those practices that had less than $25 \%$ pediatric exposure accounted for $27 \%$ of responses. Safety IV catheters were available in only $9(56 \%)$ hospitals. When available, only $56 \%$ of respondents reported using the catheters routinely. Physical retraction of the needle $(83 \%)$ was the most common safety mechanism encountered. Perception of safety IV catheters and performance satisfaction are displayed in table 1. Problems with awkward handling and poor blood flashback visualization were identified. Seven respondents reported 15 contaminated IV needlestick injuries. Thirty five percent did not know if their disability insurance protected them against infections acquired through work.

DISCUSSION: Canadian pediatric anesthesiologists do not view safety IVs with high regard. Market penetration is limited. Reasons include perceived functional deficiencies. Pediatric patients may be inappropriately viewed as being "safe" as reflected by the high underreporting rate $(45 \%)$ of needle-stick injuries and unwillingness to undergo antiviral prophylaxis (80\%). Use of safety IV catheters has been legislated in some jurisdictions and is imminent in others. Formalizing relationships with industry and local occupational health and safety committees may improve the design and implementation of safety IV catheters.

REFERENCES: [1] Anesthesiology 1998; 89(6):1362-1372 
Table 1 Perception of Safety IV Catheters and Performance Satisfaction

\begin{tabular}{|l|c|c|c|c|c|}
\hline \multicolumn{1}{|c|}{ Survey Question } & $\begin{array}{c}\text { Str. agree } \\
\text { N (\%) }\end{array}$ & $\begin{array}{c}\text { Agree } \\
\text { N (\%) }\end{array}$ & $\begin{array}{c}\text { Neutral } \\
\text { N (\%) }\end{array}$ & $\begin{array}{c}\text { Disagree } \\
\text { N (\%) }\end{array}$ & $\begin{array}{c}\text { Str. Disagree } \\
\text { N (\%) }\end{array}$ \\
\hline $\begin{array}{l}\text { Safety IV catheters should } \\
\text { be mandatory }\end{array}$ & $8(6 \%)$ & $38(31 \%)$ & $20(16 \%)$ & $27(22 \%)$ & $31(25 \%)$ \\
\hline $\begin{array}{l}\text { Safety IV catheters reduce } \\
\text { needle-stick injuries }\end{array}$ & $21(17 \%)$ & $38(31 \%)$ & $25(20 \%)$ & $31(25 \%)$ & $9(7 \%)$ \\
\hline $\begin{array}{l}\text { Safety IV catheters reduce } \\
\text { quality of patient care }\end{array}$ & $7(6 \%)$ & $33(27 \%)$ & $31(25 \%)$ & $29(24 \%)$ & $23(19 \%)$ \\
\hline \multicolumn{1}{|c|}{ Survey Question } & $\begin{array}{c}\text { V. Satisfied } \\
\text { N (\%) }\end{array}$ & $\begin{array}{c}\text { Satisfied } \\
\text { N (\%) }\end{array}$ & $\begin{array}{c}\text { Neutral } \\
\text { N (\%) }\end{array}$ & $\begin{array}{c}\text { Unsatisfied } \\
\text { N (\%) }\end{array}$ & $\begin{array}{c}\text { V. Unsatisfied } \\
\text { N (\%) }\end{array}$ \\
\hline $\begin{array}{l}\text { Safety IV catheter } \\
\text { performance }\end{array}$ & $25(33 \%)$ & $17(22 \%)$ & $6(8 \%)$ & $21(28 \%)$ & $7(9 \%)$ \\
\hline
\end{tabular}

